LIFE Tritium Processing: A Sustainable Solution For Closing The Fusion Fuel Cycle

S. Reyes, T. Anklam, D. Babineau, J. Becnel, R. Davis, M. Dunne, J. Farmer, D. Flowers, K. Kramer, J. Martinez-Frias, R. Miles, C. Taylor

August 27, 2012 
This document was prepared as an account of work sponsored by an agency of the United States government. Neither the United States government nor Lawrence Livermore National Security, LLC, nor any of their employees makes any warranty, expressed or implied, or assumes any legal liability or responsibility for the accuracy, completeness, or usefulness of any information, apparatus, product, or process disclosed, or represents that its use would not infringe privately owned rights. Reference herein to any specific commercial product, process, or service by trade name, trademark, manufacturer, or otherwise does not necessarily constitute or imply its endorsement, recommendation, or favoring by the United States government or Lawrence Livermore National Security, LLC. The views and opinions of authors expressed herein do not necessarily state or reflect those of the United States government or Lawrence Livermore National Security, LLC, and shall not be used for advertising or product endorsement purposes.

This work performed under the auspices of the U.S. Department of Energy by Lawrence Livermore National Laboratory under Contract DE-AC52-07NA27344. 


\title{
LIFE TRITIUM PROCESSING: A SUSTAINABLE SOLUTION FOR CLOSING THE FUSION FUEL CYCLE
}

\author{
S. Reyes ${ }^{1}$, T. Anklam ${ }^{1}$, D. Babineau ${ }^{2}$, J. Becnel ${ }^{2}$, R. Davis ${ }^{3}$, M. Dunne ${ }^{1}$, J. Farmer ${ }^{1}$, D. Flowers ${ }^{1}$, K. Kramer ${ }^{1}$, \\ J. Martinez-Frias ${ }^{1}$, R. Miles ${ }^{1}$, C. Taylor $^{4}$ \\ ${ }^{1}$ Lawrence Livermore National Laboratory, Livermore, CA USA, reyes20@llnl.gov \\ ${ }^{2}$ Savannah River National Laboratory, Aiken, SC, USA \\ ${ }^{3}$ Savannah River Site, Aiken, SC, USA \\ ${ }^{4}$ Los Alamos National Laboratory, Los Alamos, NM, USA
}

The Laser Inertial Fusion Energy (LIFE) power plant is being designed to deliver a transformative source of safe, secure, sustainable electricity, in a time scale that is consistent with the global energy market needs. The LIFE market entry plant will demonstrate the feasibility of a closed fusion fuel cycle, including tritium breeding, extraction, processing, re-fueling, accountability and safety, in a steady-state power-producing device. While many fusion plant designs require large quantities of tritium for startup and operations, a range of design choices made for the LIFE fuel cycle act to reduce the inprocess tritium inventory. The high fractional burn-up ( $30 \%)$ in an Inertial Fusion Energy (IFE) capsule relaxes the tritium breeding requirements, while the use of only milligram quantities of fuel per shot and choice of a pure lithium heat transfer fluid substantially reduce the amount of material entrained in the facility. Additionally, the high solubility of tritium in the lithium breeder is expected to mitigate the need for development of permeation barriers in the engine systems, normally required to control routine releases within the allowable regulatory limits.

The present paper offers an overview of the design of the LIFE fuel cycle, including a summary of the technology development plan consistent with the delivery schedule of the LIFE market entry plant.

\section{INTRODUCTION}

The LIFE power plant [1,2] is a laser-based indirectdriven fusion energy system that uses a deuterium-tritium (DT) fuel cycle to provide baseload electricity with attractive safety and licensing characteristics, and commercially competitive capital cost intensity and cost of electricity. The technical basis of LIFE can be considered as the following separable systems:

- a laser driver to convert electricity into light,
- a fusion system to convert light into a hot working fluid, via the transport of neutrons,

- a balance of plant to convert this heat into electricity,

- $\quad$ a fuel cycle, and the associated fuel transport and injection system.

Figure 1 shows a schematic of the LIFE fusion system, referred to as the engine.

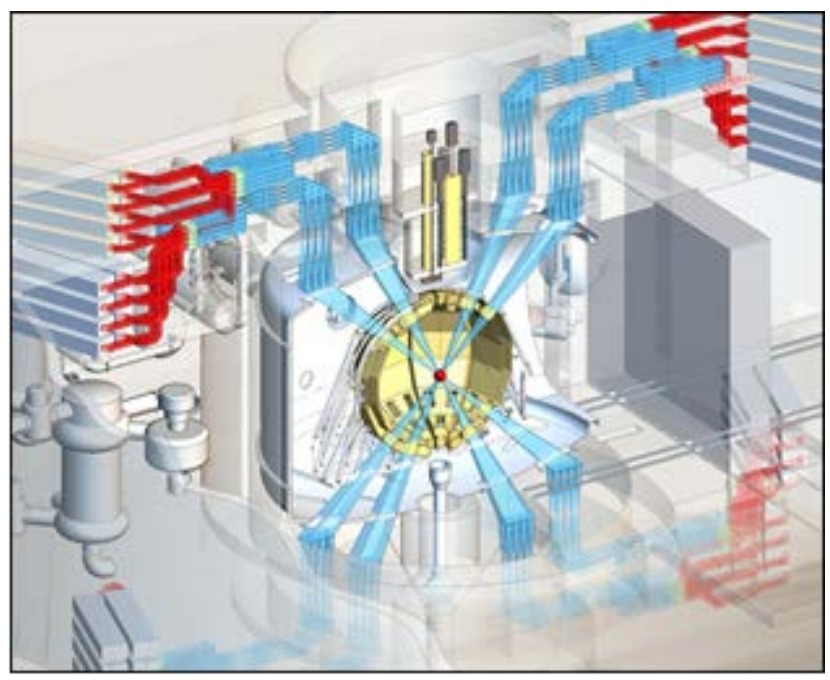

Fig. 1. Cross-section of the fusion operations area showing the main components of the LIFE engine.

The present paper focuses on the LIFE fuel cycle and provides an overview of the main systems involved in the LIFE fuel cycle, including engine recovery, processing and fabrication. The LIFE fuel assembly is based on a fusion target design that uses the physics scheme currently being tested at the Lawrence Livermore National Laboratory (LLNL) on the National Ignition Facility (NIF) [2]. Targets for LIFE power plants are 
injected into a multi-meter-sized chamber, tracked inflight, and engaged by the driver system with enough accuracy to initiate fusion with high reliability. The fusion reaction is created when 384 lasers focus onto the fusion target assembly: a capsule made of 50/50 mix of DT inside a hohlraum [3].

\section{OVERVIEW OF THE LIFE FUEL CYCLE}

The LIFE fuel cycle encompasses the engine equipment that recovers the un-spent and the bred fuel from the engine systems, the Tritium Plant equipment that processes such fuel and conditions it for target manufacturing, and finally, the target manufacturing and transport/injection equipment. The design of LIFE fuel processing equipment is based on the concept of "line replaceable units” (LRUs), allowing for high availability of the tritium systems and reduced tritium inventories in the facility. The pre-conceptual outline diagram of the fuel cycle is shown in Figure 2.
Tritium Plant equipment (light isotope purification, isotope separation, storage/delivery, detritiation, analytical and process support systems) and the target processing systems. Not explicitly shown in the simplified diagram are the tritium waste handling and recovery stations and the tritium shipping, receiving and accountability management areas.

The LIFE engine is filled with a low density Xe gas $(\sim 6 \mu \mathrm{g} / \mathrm{cc})$ that protects the structural walls from the fusion target emissions. The Chamber Gas Handling System (CGHS) must remove exhaust gas from the chamber, separate fusion debris from the gas stream and separate un-burned DT from the xenon chamber gas.

In order to close the fuel cycle, tritium is primarily produced in the engine blanket by neutron absorption and transmutation of the $\mathrm{Li}^{6}$ in the lithium breeder. The choice of a self-cooled lithium-breeding blanket (instead of a lithium bearing salt or alloy) is key for a sustainable fusion fuel cycle, as it allows for an optimum neutron economy and a tritium breeding margin large enough to

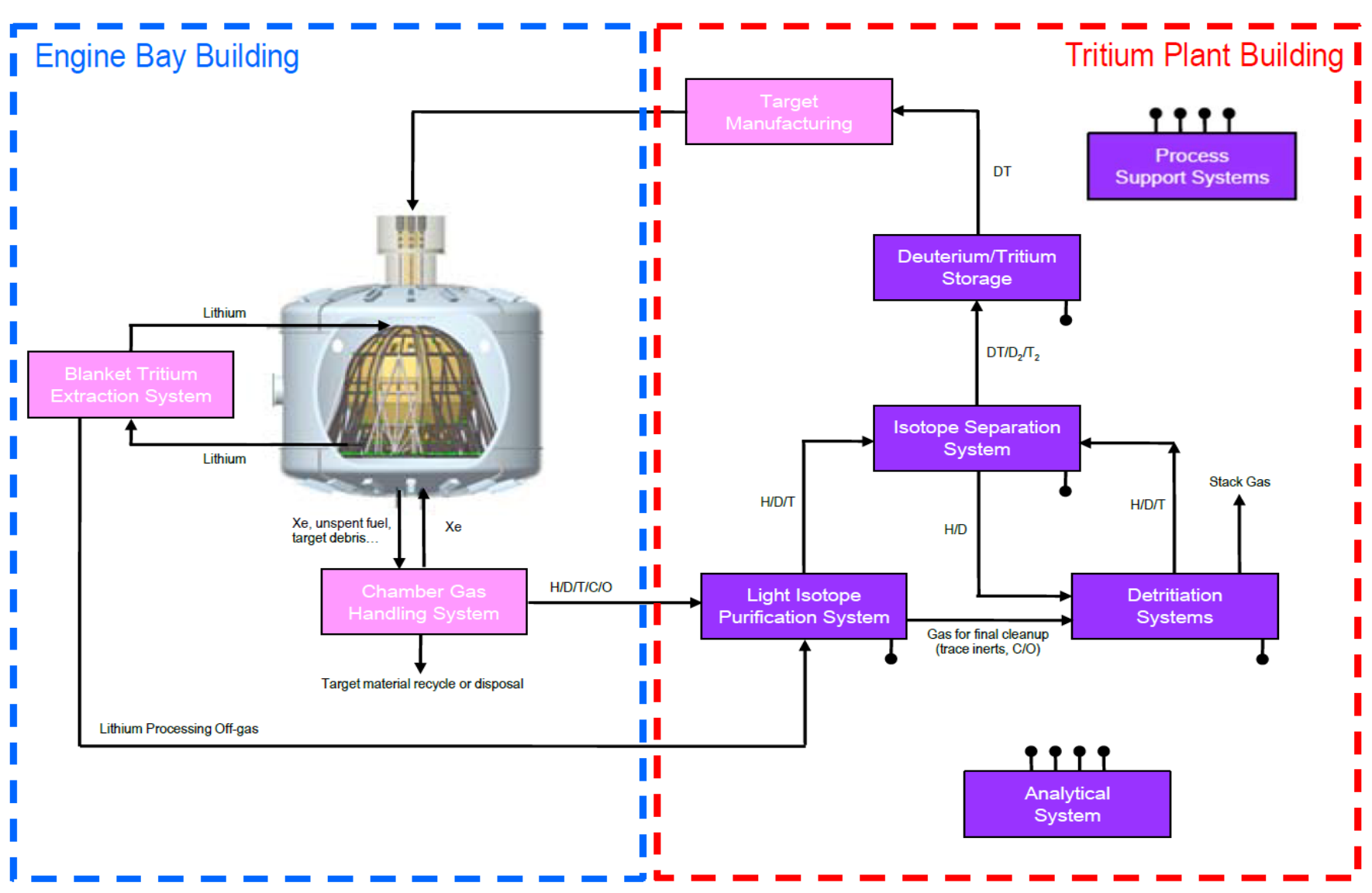

Fig. 2. Simplified LIFE Fuel Cycle diagram. The darker fill boxes represent the main Tritium Plant systems.

The simplified diagram includes the tritium processing systems related to the LIFE engine (blanket and chamber gas tritium extraction systems), the major cover potential losses and uncertainties. The relatively high tritium breeding ratio $(\mathrm{TBR}=1.27)$ eliminates the need of a beryllium multiplier and its associated cost and toxicity issues. In addition, the high solubility of tritium in the lithium leads to very low permeation rates, alleviating the regulatory concerns about routine releases. 
The Lithium Tritium Recovery System must efficiently extract the bred tritium, so that the steady state inventory mobilizable in case of an accidental spill remains below the safety limits (achievable with a tritium concentration $\sim 0.1$ wppm).

The gas streams recovered from the chamber gas and the lithium blanket are directed towards the Tritium Plant, where the fuel is purified and processed in order to produce new targets. The Tritium Plant will be required to have high up-time and availability to process such gas streams, and will be used for tritium accountability and other functions even when the remainder of the plant is in maintenance. The following high level processing functions are performed by the LIFE Tritium Plant:

- receipt of tritiated gas streams (chamber exhaust, blanket extraction purge gas) during normal operations and other phases of operation (pump down, wall conditioning, maintenance),

- separation into two streams, hydrogen isotopes $\left(Q_{2}\right)$ and detritiated impurities,

- $\quad$ conditioning of the impurity stream prior to its rejection to the environment,

- $\quad$ isotopic separation of the $\mathrm{Q}_{2}$ stream, and

- $\quad$ storage and delivery of the deuterium and tritium fractions prior to sending them to the target filling facility.

The Tritium Plant also handles incoming and outgoing gas shipments including tritium, provides handling and storage of gaseous radioactive materials for decay, performs process monitoring, tritium accountability and inventory measurements to maintain the in-plant inventory. Additional functions, such as the analysis of gases, evacuation of process loops, process control and monitoring are carried out to support the primary functions listed above. It is expected that the Tritium Plant may also include detritiation systems and process utility systems with specialist HVAC equipment for spaces within the plant that may contain tritium. Other related facilities will be necessary to handle and store tritiated and mixed tritiated/radioactive material from the LIFE plant. The LIFE Tritium Plant systems are interconnected and highly dependent on the engine processing systems and the target manufacturing systems as shown in the functional block diagram of Figure 2.

In the following sections we describe the preconceptual design of each of these systems.

\section{DESCRIPTION OF THE ENGINE TRITIUM SYSTEMS}

\section{III.A. Chamber Gas Handling System}

The CGHS is an integral part of the LIFE engine operation, capturing fusion waste and recovering unburned fuel. The fusion process utilizes approximately only one-third of the tritium injected with the target, so the remaining two-thirds must be recovered to achieve self-sustaining and economic operation. Figure 3 shows a sketch of the LIFE baseline target design. It consists of a low-Z capsule ablator with a thin layer of deuteriumtritium (DT) on the inner diameter enmeshed in a lowdensity foam. The capsule is held in the center of a rugby-shaped hohlraum consisting of a high-Z material. Two shields are placed along the axis of the hohlraum to reflect the infrared (IR) radiation emanating from the chamber walls. The laser entrance hole (LEH) windows keep the hot chamber gases from heating the DT capsule layer.

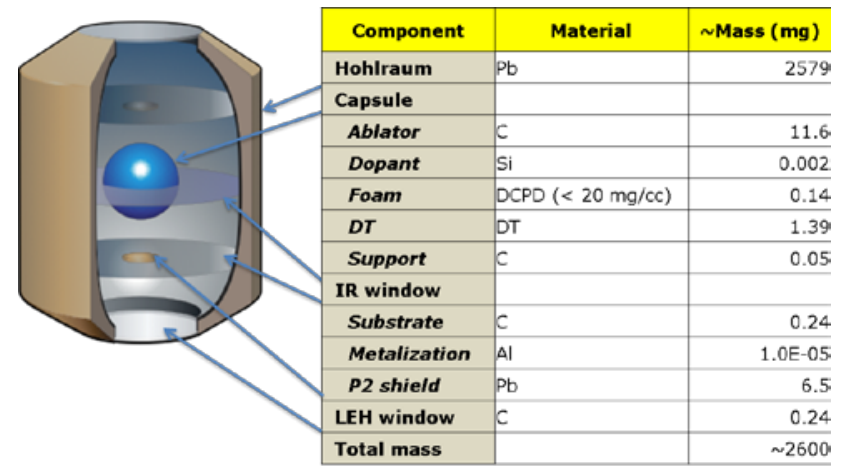

Fig. 3. Schematic of the LIFE target

The materials used in target fabrication will be mixed with the chamber gas exhaust and will ultimately have an impact in the technology selection for fuel recovery. The hohlraum surrounding the fusion fuel is composed largely of lead, so continuous lead removal is needed to maintain the chamber at operating conditions. Therefore, the first stage in the CGHS is devoted to initial gas cooling and lead separation. Once lead is removed, the cooled chamber exhaust gas is cooled further and circulated back to the chamber using a blower or compressor. The recirculated gas is reheated to chamber operating conditions. Chamber clearing occurs at a flow rate of $1 \mathrm{~kg} / \mathrm{s}$, which corresponds to removal of $1 \%$ of the chamber volume per fusion detonation. A fraction (10\%) of the chamber exhaust is extracted, compressed, and further processed for tritium recovery and other purification steps. These steps involve reacting the mixture to separate hydrogen isotopes from other molecules, followed by several cryogenic distillation steps to isolate those hydrogen isotopes and send them to the Tritium Plant for further fuel conditioning.

\section{III.B. Lithium Tritium Recovery System}

Liquid lithium is being considered as the heat transfer and breeding blanket material for the LIFE engine due to its many virtues: low density, high thermal capacity, good thermal conductivity, high potential to breed tritium due 
to its high neutron capture cross-section, and high affinity for hydrogen isotopes that minimizes tritium permeation. High hydrogen affinity, however, complicates tritium recovery while operational safety demands a low tritium inventory. Contact of lithium with water must be avoided at all times.

The tritium recovery system is designed to keep the tritium steady state inventory of the LIFE engine power plant under $50 \mathrm{~g}$. The amount of liquid lithium in LIFE pilot plant is $~ 500$ metric tons, thus the desired steady state concentration of tritium in liquid lithium is 0.1 wppm. Only a fraction of the liquid lithium is processed to recover tritium at the breeding rate. LIFE uses molten salt extraction to recover the tritium at high temperature $\left(\sim 575^{\circ} \mathrm{C}\right)$, before the intermediate heat exchanger. Maroni et al. [4] were the first to propose the use of molten salt extraction for tritium recovery from liquid lithium. The molten salt extraction method consists of four steps:

1. Lithium containing trace tritium and molten salt (lithium halides) are mixed, and the LiT is preferentially extracted into the salt.

2. Lithium and salt are separated in a centrifugal contactor

3. The salt is circulated to an electrolyzer and the LiT is oxidized to form $T_{2}$, which is swept from the salt by bubbling argon

4. The argon is circulated to a getter where tritium is recovered

Figure 4 shows a simplified diagram of the LIFE blanket tritium extraction process.

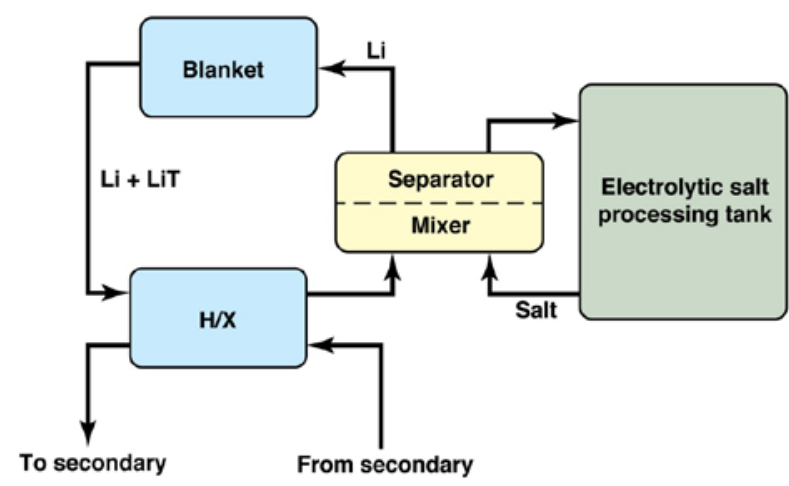

Fig. 4. Tritium is removed from liquid lithium by intimate contact with a molten salt and subsequent electrolysis

\section{DESCRIPTION OF THE TRITIUM PLANT EQUIPMENT}

Over the last two years, an outline design for the LIFE Tritium Plant has been developed. Work performed to date included definition of the processing function(s) and high-level requirements of each system, identification of interfaces and selection of candidate technologies. The next few sections provide a summary of the design of the main systems involved in the tritium plant (i.e., dark-color filled blocks in the diagram from Figure 2).

\section{IV.A. Light Isotope Purification System}

The Light Isotope Purification System (LIPS) will be the entry point into the Tritium Plant for feeds from the LIFE engine (chamber gas and blanket systems) and will perform preliminary processing of these streams. Its most important functions are to break down hydrogen containing molecules, separate the hydrogen from nonhydrogen containing species, and to purify the hydrogen stream sufficiently for it to be sent to the Isotope Separation System. Additionally, this system will have to detritiate the process off-gases sufficiently for them to be sent to final clean-up by the Detritiation Systems. Finally, this system will also serve the function of tritium recovery from process water that may be formed in the normal operation of the systems, during maintenance or offnormal conditions. At this design stage, various technology candidates have been identified for the LIFE LIPS system, which included a combination of Catalytic Oxidation Reactors, Molecular Sieve Beds, Permeators, and Palladium Membrane Reactors (PMRs) [5]. The design of this system is currently being optimized to further integrate the LIPS, CGHS and tritium processing sub-systems. Down selection of technologies will follow this optimization process. As can be seen in Figure 2, the LIPS has interfaces with the engine systems, and other Tritium Plant equipment. Of these, the interface with CGHS is clearly the strongest and most complex, to the extent that some design options currently under evaluation consider these two systems as in integrated unit.

\section{IV.B. Isotope Separation System}

The main function of the Isotope Separation System (ISS) is to separate the hydrogen species into releasable and storable isotopic combinations. The ISS is expected to produce releasable gas streams $\left(\mathrm{H}_{2} / \mathrm{HD}\right)$ and storable $\mathrm{T}_{2}, \mathrm{D}_{2}$ and/or DT mixes with purities sufficient to be sent to the Deuterium/Tritium Storage System. It is assumed that the releasable $\mathrm{H}_{2} / \mathrm{HD}$ streams will be sent to the Detritiation System before atmospheric release through the elevated release point. The secondary function of the ISS is to recover and recycle $D_{2}$ to be sent towards storage. The ISS is expected to be based upon one or more of the following technologies; thermal cycling absorption process (TCAP) [6], other chromatographic techniques [7], and/or cryogenic distillation [8]. 


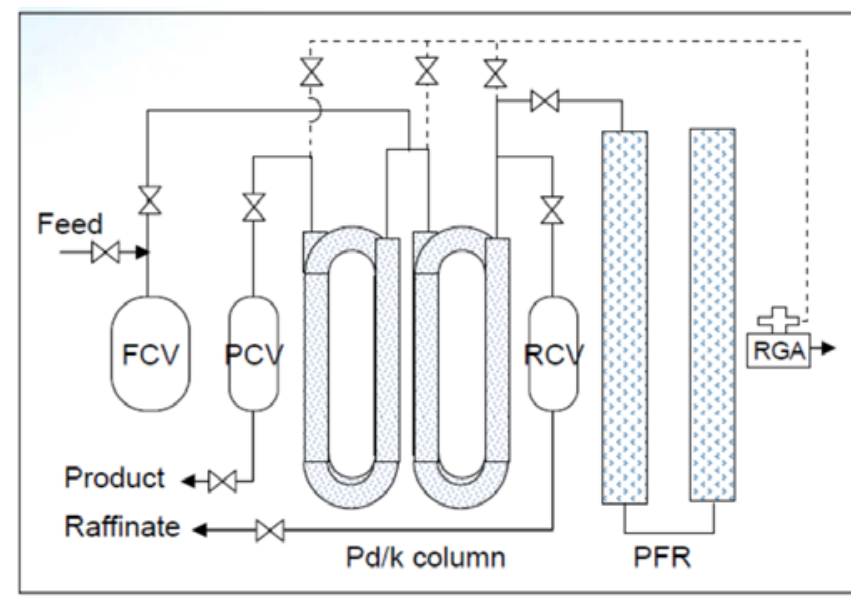

Fig. 5. General arrangement of a TCAP column

Figure 5 shows an example of a typical TCAP unit for isotope separation. The process portion of the TCAP system consists of a column packed with palladium deposited on kieselguhr ( $\mathrm{Pal} / \mathrm{k})$ and a plug-flow-reverser (PFR) packed with plain kieselguhr. Kieselguhr, a form of diatomaceous earth, has a low pressure drop for gas flows in the column and provides a large surface area for deposition of the palladium metal. The thin layer of palladium on kieselguhr readily absorbs hydrogen gas. TCAP operates on the principle similar to a gas chromatograph using a palladium column, but in a semicontinuous manner. One end of the column is dead-ended with the other end connected to the PFR. The hydrogen feed for isotopic separation is added at a fixed location on the column, a heavy isotope enriched stream is withdrawn at the dead end of the column (Product end), and a heavy isotope depleted stream is withdrawn at the end of the column where it is connected to the PFR (Raffinate end). The column is thermally cycled. Cascading columns in sequence can achieve separation of $\mathrm{H}, \mathrm{D}$, and T. However TCAP may lose its smaller footprint advantage when high rates of gas must be processed.

Although TCAP currently appears as a promising option for LIFE, ongoing work on LIPS design optimization may have an impact in the technology choice for the ISS. As in the case of the LIPS, assuming that various of the above technologies can fulfill the LIFE system requirements, the leading design criteria will continue to be the minimization of tritium inventories, for enhanced safety and licensing characteristics.

\section{IV.C. Deuterium/Tritium Storage System}

The DT Storage (DTS) is the system that receives and stores the DT, $\mathrm{D}_{2}$ and/or $\mathrm{T}_{2}$ as separated from the ISS, and supplies fuel as required by the Target Manufacturing systems. Additional functions of the DTS are to act as the major accountability center for the measurement of deuterium and tritium inventories in the LIFE facility, to receive and distribute all gasses to LIFE tritium wetted systems, to receive pure $T_{2}$ from the Blanket Tritium Extraction System and to ship excess gasses (HD, $\mathrm{D}_{2}$ and $3 \mathrm{He}$ ) from the facility. Also, the DTS is expected to provide sufficient capacity to place the entire "at risk" tritium inventory onto beds to reach a safe state in case of accident/incidents in the Tritium Processing area. The LIFE DTS will utilize temperature controlled metal hydride bed technology for the storage of hydrogen isotopes [9].

\section{IV.D. Analytical Systems}

The Analytical System (ANS) interfaces with all the other systems within the LIFE Tritium Plant to provide in-process tracking of tritium, deuterium and other gases It is expected that the individual processes within the Tritium Plant will have dedicated process monitoring and control capability and not rely on the ANS for this level of process control. However, each of these processes may be required to report to the ANS to determine the amounts and locations of materials within the Tritium Plant. The Tritium Plant will switch to a non-processing mode when inventories need to be determined by the DTS in-bed calorimeters for accountability. The ANS will have also a strong interface with the control room for the LIFE fuel processing systems.

Technologies for the tracking of radioactive gas species are well established and may include ionization chambers, gas chromatography, high/low resolution mass spectrometers, residual gas analyzer (RGA), laser Raman spectroscopy, Fourier transform infrared spectroscopy (FTIR) and liquid scintillation counters.

\section{IV.E. Detritiation Systems}

The LIFE Detritiation Systems (DS) will perform several important functions, including some that are relevant for safety such as the final cleanup of all process streams, detritiation of atmosphere of equipment enclosures, ventilation and HVAC streams. Final detritiation of remaining low-tritium concentration in water is also accomplished by the DS. The DS will ensure that all emissions within LIFE are sufficiently clean to allow for release to the environment through the elevated release point or stack. Other secondary functions of the DS will be to provide pressure control (negative) within the equipment gloveboxes or enclosures, so as to provide an inert (nitrogen) atmosphere within these gloveboxes/enclosures for deflagration prevention.

Based on the available technologies that have been proven to date [10], it is expected that this system will be made up of a combination of Catalytic Oxidation Reactors, Molecular Sieve Beds, Scrubber Columns, and PMRs. 


\section{IV.F. Process Support Systems}

The Process Support System (PSS) serve as a centralized area for maintenance of tritiated process parts, subsystems pumps etc. The PSS will provide evacuation and backfill capability for preparation of process lines for maintenance and subsequent post maintenance testing and restoration from maintenance. This system will also provide process instrumentation calibration standards (pressure / temperature), and will be the major interface between the HVAC and low-tritium process evacuation systems and the DS.

\section{FUEL MANUFACTURING}

The Fuel Manufacturing activity, followed by the transport and injection of new fuel targets in the engine, is the back end of the LIFE fuel cycle. The central role of the in-plant Fuel Manufacturing activity is to deliver fuel targets in a physical form that complies with the requirements of implosion physics and in a sufficient quantity and price to supply affordable electricity to the grid. There are four major categories of target components/processes: capsule fabrication, hohlraum fabrication, membrane fabrication and the assembly operations. The current assumption is that capsule, membranes and hohlraum are manufactured separately and combined into subassemblies. Only the final assembly and DT fill is performed in the in-plant Target Manufacturing area.

The manufacturing techniques are highly dependent on the choice of material. This involves consideration of several factors: the implosion physics; material cost and availability; fabrication technique; thermal, mechanical and optical properties to withstand the forces of manufacturing and injection into the hot chamber; the ability to recover the chamber debris; limiting laser propagation interference; impact on the tritium plant; and enabling recycle or disposal of waste products. By limiting the number of different low-cost materials used to build a target, the set of processes that must be developed can be reduced.

All parts of the LIFE target fabrication process will be automated to achieve the cost and throughput objectives. Based on industry consultation to date, assembly of the target parts can be achieved through use of robotics and custom-design machinery. Self-aligned parts and fixturing can be used to attain the required tolerances.

\section{TRITIUM CONFINEMENT}

The importance of minimization of tritium inventories and of low permeation (i.e., low routine releases) for safety and regulatory attractiveness has already been emphasized throughout the paper. As specified in the DOE Fusion Safety Standards [11, 12], confinement of hazardous materials, and in particular of tritium, is the most fundamental safety function, where confinement refers to all types of physical and functional barriers which provide protection against the spread and release of hazardous materials. Confinement is implemented by:

- Sets of successive physical barriers or envelopes (including process enclosures, secondary confinement, etc.) around each of the principal source terms (in-vessel, fuel cycle, heat transfer systems, maintenance bay and radwaste facilities, if applicable)

- Systems (pressure suppression systems, ventilation systems...), which provide the functions of pressure control and removal of radioactive materials from these envelopes

In addition, restricting the quantities of mobilizable radioactive materials is employed to reduce hazards. Therefore, it is a primary criteria in the design of the LIFE fuel cycle and tritium processing systems that the amount of tritium that can be released in case of any off-normal event remains below the safety limit for no public evacuation (1 rem).

The confinement barriers are independent from each other and passive where possible with minimal dependence on new components that cannot practically be tested in the appropriate service environment before construction. Every radioactive inventory is contained in its vessel, process piping, component, etc. which serves as the first confinement barrier. This confinement barrier is designed to have high reliability to prevent releases. Another barrier is provided usually close to the first one to:

- Protect personnel and limit the spread of contamination from leaks

- Mitigate consequences in the event of failure of the first barrier to assist in meeting project release guidelines

The LIFE tritium systems design will maximize structural and spatial separation and independence from the first confinement barrier to prevent a common failure mode of both barriers. Pressure gradients are being designed such that air flow is from lower to higher contamination, and exhaust from rooms that may become contaminated will be treated by filters and/or detritiation systems (if necessary) and will be monitored.

Additionally, the design of tritium systems will consider protection against hazards from hydrogen fires and explosions. In addition to the confinement approach described above, additional controls will be implemented to detect and mitigate the potential introduction of air into the proximity of tritium processing equipment.

\section{CONCLUSIONS}


The LIFE market entry plant will demonstrate the feasibility of a closed fusion fuel cycle, including tritium breeding, extraction, processing, re-fueling, accountability and safety, in a steady-state power-producing device. The LIFE fuel cycle encompasses the engine equipment that recovers the un-spent and the bred fuel from the engine systems, the Tritium Plant equipment that processes such fuel and conditions it for target manufacturing, and finally, the target manufacturing equipment. This paper provides an overview of main functional requirements and technology candidates for all of these systems.

Some unique features of the LIFE fuel cycle include a high tritium fuel burn-up fraction, a relatively high tritium breeding ratio (through the use of a liquid lithium breeder), and low tritium permeation from the heat transfer fluid (due to the high solubility of tritium in lithium). The use of only milligram quantities of fuel per shot and choice of a pure lithium fluid substantially reduce the amount of material entrained in the facility. Additionally, the leading criteria in the design of LIFE tritium processing systems is that the amount of inventory that could be mobilized in case of any accident remains below the safety limit to avoid public evacuation.

Ongoing work is being devoted to down-select technology choices and ensure robust interface management. As the project evolves, all aspects related to tritium confinement and accountancy will remain as key considerations in the design of the LIFE power plant.

\section{ACKNOWLEDGMENTS}

This work was performed under the auspices of the U.S. Department of Energy by Lawrence Livermore National Laboratory under Contract DE-AC52-07NA27344.

\section{REFERENCES}

1. M. Dunne, et al, Fusion Science and Technology, 60, 19 (2011)

2. E. Moses, Fusion Science and Technology, 60, 11 (2011)

3. R. Miles, et al., Fusion Science and Technology, 60, 61 (2011)

4. V. A. Maroni, et al., Nucl. Technol., 25, 83 (1975) and US Patent 3,957,597 (1976).

5. S. A. Birdsell, R. S. Willms, "Tritium recovery from tritiated water with a two-stage palladium membrane reactor," Proceedings of the Symposium on Fusion Technology, 953 (1998).

6. L. K. Heung, H. T. Sessions, X. Xiao, H. L. Mentzer, Fus. Sci. and Technol., 56, 1471 (2009).

7. C. H. Cheh, Journal of Chromatography A, 658-2, 283 (1994).
8. J. R. Bartlit, R. H. Sherman, R. A. Stutz, W. H. Denton, Cryogenics, 19-5, 275 (1979).

9. L. K. Heung, "Design of metal hydride vessels for processing tritium,” WSRC Report, WSRC-MS2001-00179 (2001).

10. S. Beloglazov, et al., "Preliminary design of the ITER tokamak complex and hot cell facility detritiation systems," to appear in the Proceedings Tritium 2010.

11. DOE-STD-6002-96, Safety of Magnetic Fusion Facilities: Requirements, US Department of Energy (1996).

12. DOE-STD-6003-96, Safety of Magnetic Fusion Facilities: Guidance, US Department of Energy (1996). 